\title{
End-of-life care - Perceptions of Public
}

\author{
Mrs. Vineetha Jacob ${ }^{1}$, Dr.Vina Ravi Vaswani ${ }^{2}$ \\ ${ }^{1}$ (Dept. of Psychiatric Nursing, Yenepoya Nursing College, Yenepoya University, India) \\ ${ }_{2}^{2}$ (Director, Center for Ethics and HOD, Dept of Forensic Medicine, Yenepoya Medical College, Yenepoya \\ University, India)
}

\begin{abstract}
Background: Medical technology has advanced to such an extent that it can keep people alive even if the last resort to make them well is not possible. Issues regarding these treatment measures will continue if patient autonomy is not respected. The objective of this study was to assess the preferences of the public regarding end-of-life care.

Methods: A semi-structured questionnaire on end-of-life care preferences and decision-making was used to collect data from ten people who were recruited from the general population using theoretical sampling. Informed consent was obtained prior to data collection.

Results: All the informants expressed the wish to receive pain medication and antibiotic treatments. Except one, no one wanted to take the dosages in excess quantity if it would shorten the lifespan. Majority of them expressed that they did not want to be supported by artificial respiration, if breathing stops on its own. Provision for writing a living will regarding end-of-life care was also supported by majority of the participants.

Conclusion: This study revealed that most of the people do not want to continue their life by means of supporting breathing machines if there is no hope of recovery. They would like to make their own decision for end-of-life care.
\end{abstract}

Keywords - end of life care, advanced health care directives, living will, healthcare proxy, life-sustaining treatment.

\section{Introduction}

Technological advances in medical field have created ethical dilemmas faced by patients and healthcare professionals. Today the medical care has changed from paternalistic view to an area where both doctors and patients have equal decision-making authority. Artificial respirators, transplantations, antibiotic therapy, and critical care are some life prolonging measures which create confusion and raise issues in decisionmaking for patients, relatives, and doctors. Appropriate use of technology is very important if it is just for prolonging life, but at the same time the question arises: Should the technology be used even if it increases agony at the end-of-life and takes away the compassionate care at the time of death?

Medical technology has advanced to such an extent that it can keep people alive even if the last resort to make them well is not possible. Whether the patient wants such a treatment or care - which would not cure them but increases their suffering - is not given due thought. The rights of the patient include autonomy, and all patients have a right to refuse medical interventions [1] from blood transfusions and antibiotics to respirators, artificial hydration, and nutrition. In US, the decision regarding termination of their own care also can be taken by a competent patient who is suffering from an incurable disease. In India such a strategy does not exist. Endof-life care remains a challenge as long as we do not consider patient's autonomy to take decisions. Home would be the most preferred place for death by terminally ill patients, spending time with loved ones and performing social and pertinent rituals. Dying with dignity, with peace and without pain is considered as good death in any Indian society[1]. The possibility to say goodbye to loved ones, dying with dignity, and being able to decide about end-of-life care and dying free of pain are considered the characteristics of a good death by Dutch general public [2]. Withdrawal of futile life-sustaining treatment was supported by a large majority of participants, reported in a study conducted in Korea [3]. A study conducted in Japan regarding public's attitude towards advanced directives revealed that $73 \%$ of the participants wanted to decide by themselves about their treatment and they did not want life-sustaining procedures that helped only to prolong the process of dying if their condition was terminal and incurable[4]. Findings from another study regarding end-of-life care conducted among African Americans have given the implications to encourage the patient to be the primary decisionmaker and to ensure that the dying person is not infantilized [5]. Being compassionate and understanding patient's values and beliefs is very much needed for good end-of-life care. But, are we considering patient's opinion about his end-of-life care?

Quality of end-of-life care is increasingly recognized as an ethical obligation of healthcare providers. Even though patient autonomy is to be respected by involving them in making decisions about their end-of-life care, 
many times it does not happen. Advances in healthcare, if only prolongs the life without recovery or improving the quality of life, will give rise to new ethical dilemmas. Healthcare providers should respect the autonomy of the clients and give them the freedom to take decisions of their own. Patient's preference of what kind of care they want to receive at the-end-of life is very important. What is the client's meaning about a good death? If they are given the chance to make a decision regarding their own end-of-life care, what will be their decision? Whom do they want by their side during their last breath? What is that they want in the will? Are they respected? To identify and describe elements of end-of-life care from participant's perspectives this study is being undertaken. This will help to explore the suitability of the system concerned with end-of-life decisionmaking.

\subsection{Research Design}

\section{Material and Methods}

Phenomenological enquiry in qualitative research design was utilized for the study. The focus of phenomenological enquiry is what people experience in regard to some phenomenon and how they interpret those experiences. In this study the investigator focused on people's perceptions regarding end-of-life care.

\subsection{Sampling Plan}

Theoretical sampling technique was used to select the samples for the study. Regardless of the initial selection, the researcher selected ten samples to know the difference in perception, based on contrast characteristics of already involved participants.

\subsection{Tools and Technique}

A demographic proforma and a semi-structured open ended questionnaire were used to collect the data.

\subsection{Data collection}

Demographic proforma and semi-structured questionnaire was prepared by the investigator. The ethical clearance from the Institutional Ethics Committee was obtained prior to starting study. The tool was pre-tested on two subjects. They could understand the questions. After obtaining informed consent from the participants, the questionnaire was administered. After the questionnaire being filled, the investigator tested the trustworthiness of the data by confirming it with the participants. Then various themes were identified and the data was analyzed and recorded under each theme. Content validation was done by the experts.

\section{Analysis and interpretation}

Total of ten participants, six males and four females between the age 20 and 73 participated in the study. Samples included two students, five health professionals, two other professionals and one elderly person. Among them six were married and four were unmarried. Samples were from Christian, Hindu and Muslim backgrounds. All the participants had belief in God.

Major themes that emerged in the analysis of transcripts were:

1. Alleviation of pain and infection.

2. Life extension measures.

3. Decision-making at the end-of-life.

4. Beliefs about good life and good death.

Alleviation of pain and infection: All the participants expressed the wish to receive pain medication when they have severe pain. No one wished to receive dosage in excess quantity if it would shorten their life span except one, and the one who wished to receive it, stated that she would like to receive dosages in excess quantity if it would reduce pain and suffering. All the participants wished to receive antibiotics if they had infection.

Life extension measures: Majority of the participants expressed that they did not want to be on a machine which give artificial respiration if they stop breathing of their own.

Responses were as follows:

"No, I don't like to remain in this world as a vegetable."

"If I stop breathing of my own, I wish to have a peaceful death."

"Life is given by God and will be taken by God. There is no need to extend it" is the opinion by senior citizen of age seventy three.

But one interesting point that came across was that those who did not wish to prolong the life with the help of artificial respirators, supported the researches related to the development of life-extending measures.

"If anybody really wants to extend their life, researches will help them."

"Each individual is different and some people like to live and some not. So life extending devices may help them." 
With regard to fluid and nutrition (via tube inserted through nose), except one, all participants expressed the wish to stop it.

"Instead on Ryle's tube for long time, I wish to die, because I don't want to suffer."

"......that is equal to extending life."

" Depends. If I know that I am a burden to my family members I don't wish to extend my life by receiving nutrition via tubes. But if my presence is needed for my family members due to any reason, I will definitely agree to receive food through tubes to keep myself alive."

Decision-making regarding end-of- life care: Majority expressed that if they are not able to communicate or incompetent to take a decision, a close relative could take decision regarding end-of-life care for the client. All of them wished the decision by the relatives to be withdrawn or withhold life extending measures. Some did not want others to take decision for them. But all the participants, except one wished to write a living will of decision regarding end-of-life care if there is a provision for it.

"I wish to decide my end-of-life care. I do not like others taking decision on my care that may be extend the life if there is no hope of living again."

"It will help family members and relatives."

"Because I wouldn't want my family to spend money on me when there is no chance of recovery or return to healthy life."

Majority of the participants wanted to spend their last hours in home.

"at home, with dear ones."

"In home with my family members want to spend happily my last hours."

One participant stated that it would be according to the disease condition and another one stated "no specific opinion."

Beliefs about good life and good death: Doing good to others, helping needy, living a healthy life, peaceful, sufficient to fulfill the responsibilities, living with happiness and difficulties at times with the dear ones were considered as good life by the participants.

Dying without pain and suffering was considered to be good death by majority of the participants. Passing away without troubling others also was considered as important by some participants.

"Dying without suffering and troubling others."

"Meeting death with pious and God fearing life."

Preparing for death, dying with dignity, telling goodbye to loved ones, feeling of life goal achievement were the events which were considered to be resulting in good death.

"Preparing for death by receiving the sacraments, as I believe those things make my soul more pure and I can reach God easily."

All the participants believed that death is a process where we join with God after our life

\section{Discussion:}

The present study revealed about people's preferences about end-of-life care decisions. People do not want to prolong their life with artificial measures if it is not helpful for a recovery. They want to die with dignity and peace. This report is consistent with previous studies conducted. A study conducted on preferences among Dutch general public for a good death revealed that the possibility to say goodbye to loved ones was considered as important for a good death by the large majority of respondents. Dying with dignity, being able to decide about treatments at the end-of-life, and dying free of pain were the other factors considered as important [2]. A study was conducted in Los Angeles identify the desired features of end-of-life medical decision-making from the perspective of elderly individuals revealed that they preferred medical interventions if they could return to his or her most valued life activities. Family's decision-making authority was important for them when functional recovery was not possible, aided by doctor's support and technical guidance [6].

\section{Conclusion}

Death is inevitable and dying is a process through which everyone should pass through. When the health condition worsens, the perceptions regarding the pain and expectations for healthcare vary from individual to individual. Understanding from the client's point of view is very essential to provide quality healthcare which is meaningful for the client. This study suggests that people do not wish to be on life-extending machines when the quality of life is not improved. They want to make their own decisions regarding their endof-life care. As clients are the consumers of healthcare, health professionals should accept clients' decisions for their own healthcare. So, provisions should be made for the clients to express their wish regarding their care.

Conflict of interest - Nil

Source of Funding- self

Ethical clearance - Ethical clearance was obtained from Ethics Committee, Yenepoya University, Mangalore. 


\section{References}

[1]. Yeolekar ME, Mehta s, Yeolekar A. End-of-life care: Issues and challenges. J Postgrad Med, 54(3).2008 July, $173-175$.

[2]. Rietjens JA, van der Heide A, Onwuteaka-Philipsen BD, van der Maas PJ, van der Wal G, Preferences of Dutch general public for a good death and associations with attitudes towards end-of-life decision-making, Palliative Medicine, 20. 2006, 685-692

[3]. Yun YH, Han KH, Park S,Park PW, Cho C, Kim S, et al. Attitudes of cancer patients, family caregivers, oncologists and members of the general public towards critical interventions at the end-of-life of terminally ill patients, CMAJ, 183(10). 2011 Jul 12, E673-679.

[4]. Miyata H, Shiraishi H, Kai I. Survey of the general public's attitudes towards advance directives in Japan: How to respect patient's preferences. BMC Medical Ethics 2006,7:11

[5]. Jenkins C, Lapelle N, Zapka JG, Kurent JE. End-of Life Care and African Americans: Voices from the community. Journal of Palliative Medicine, 8(3). 2005, 585-592.

[6]. Rosenfeld KE, Wenger NS, Kagawa-Singer M. End-of-life decision-making: a qualitative study of elderly individuals. J Gen Intern Med, 15. 2000, 620-6255. 